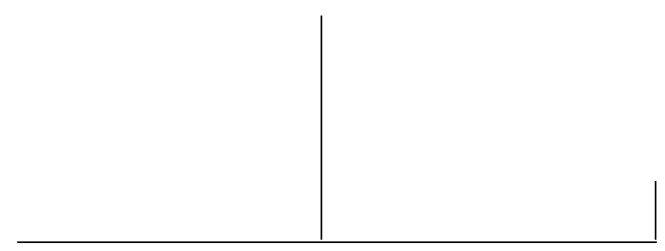

Rev. Latinoam. Psicopat. Fund., IX, 2, 279-292

\title{
Desconstruindo o alcoolismo: notas a partir da construção do objeto de pesquisa no contexto indígena
}

\author{
Maximiliano Loiola Ponte de Souza \\ Luíza Garnelo
}

A partir de uma revisão de conceitos utilizados na pesquisa sobre o uso de bebidas alcoólicas e de trabalhos nacionais que abordam a questão do uso de álcool por populações indígenas, evidencia-se a dificuldade gerada pelo uso indiscriminado da noção de alcoolismo. Apresenta-se uma proposta inicial de um modelo teórico no qual são articulados os conceitos de dependência, problemas relacionados ao uso de álcool e alcoolização, que vêm pautando os autores na construção do objeto de pesquisa no campo da saúde indígena na região do Alto Rio Negro, noroeste do Estado do Amazonas.

Palavras-chave: Alcoolismo, populações indígenas, antropologia da saúde, psiquiatria transcultural 


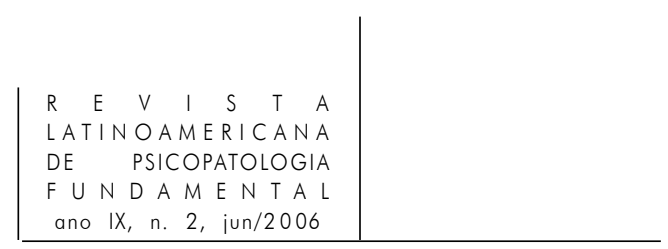

\section{Introdução}

O uso de bebidas alcoólicas acompanha a humanidade desde os primórdios, e esta prática ocupa um lugar privilegiado em diversas culturas. A partir da revolução industrial no mundo ocidental, a relação entre o homem e esta bebida vem se modificando, uma vez que ocorreu um aumento populacional nas zonas urbanas, um incremento na produção de bebidas a uma escala industrial, levando à queda nos preços e aumento da disponibilidade. Tais acontecimentos parecem ter revelado um outro lado do uso do álcool, associado à violência, à discórdia e à dor (Gigliotti e Bessa, 2004).

Desta forma, o uso de álcool e suas conseqüências passaram a ser preocupações e objetos de pesquisa ao longo do último século. Inicialmente, passou a ser interesse de estudo da biomedicina, que cunhou o termo "alcoolismo". Posteriormente, cientistas sociais passaram a se debruçar sobre o tema. Em diversos momentos as produções destes campos científicos entram em conflito, na busca de supremacia explicativa.

Nos últimos três anos tem sido objeto de nossas pesquisas a questão do uso de álcool por populações indígenas (Souza M., 2004 e 2005). Assumimos o compromisso teórico, ético e político de desconstruir a categoria "alcoolismo", evitando utilizá-la no sentido do senso comum, e tendo o cuidado de não fornecer argumentos a setores da sociedade nacional que se utilizam desta categoria para acentuar a discriminação dos grupos indígenas (Langdon, 2001). Assim, fez-se necessário a construção de um referencial que permitisse, mesmo que de forma aproximada, a apreensão deste complexo fenômeno.

O trabalho será dividido em três etapas: apresentação de uma revisão dos conceitos de dependência ao álcool (APA, 1995, OMS, 1993), problemas relacionados ao uso de álcool (Edwards et al., 1999) e processo de alcoolização (Menendez, 1982); revisão de trabalhos nacionais que abordam a questão do uso de álcool por populações indígenas; síntese de como estamos buscando agregar as experiências dos autores nacionais e articular os conceitos anteriormente apresentados na construção de nosso objeto de pesquisa.

\section{Diferentes olhares para a questão do uso do álcool}

Bertolote (1997) fez uma revisão sobre o conceito de "alcoolismo" no cenário da biomedicina. O termo alcoolismo foi cunhado por Magnus Huss 
em 1849, e para ele o alcoolismo deveria ser entendido como um quadro de intoxicação crônica pelo álcool. A descrição deste baseava-se exclusivamente nas conseqüências do uso do álcool nos diferentes órgãos e sistemas do indivíduo.

Em 1931, o Royal College of Physians, de Londres, promoveu uma inovação ao enquadrar o alcoolismo para o grupo das Doenças Mentais, deixando de ser classificada como uma doença geral ou constitucional (Bertolote,1997). Tal opção classificatória passa a ser aceita pela Organização Mundial de Saúde (OMS) a partir de 1950. Entretanto, o conceito de dependência a álcool só passa a fazer parte deste sistema classificatório a partir de 1977.

Observa-se que a descrição nosográfica dos transtornos relacionados ao álcool vem sofrendo mudanças, que se exteriorizam nos critérios da classificação. Os atuais códigos de classificação dos transtornos mentais abandonaram o termo "alcoolismo", tanto pela imprecisão conceitual, quanto pelo preconceito associado a esta expressão. Considerando os atuais códigos de classificação de doenças, os transtornos associados ao uso de álcool fazem parte de um grupo maior de transtornos: Transtornos mentais e do comportamento decorrentes do uso de substância psicoativa (CID-10; OMS, 1993), ou Transtornos relacionados a substâncias (DSM IV; APA, 1995).

Diversos são os subtipos de transtornos relacionados ao uso de álcool, sendo um deles a síndrome de dependência a álcool, caracterizado por: indícios de dependência química (abstinência e tolerância); descontrole em relação ao uso da substância; problemas de ordem física, psíquica e/ou social decorrentes do uso da mesma. É importante perceber que para o diagnóstico de dependência ao álcool, a quantidade de bebida ingerida e a freqüência de consumo não são critérios imprescindíveis.

A ampla aceitação de que a dependência ao álcool se constitui em uma doença está relacionada ao sucesso dos grupos Alcoólicos Anônimos, que explicitamente a adotam, bem como a contribuição dos trabalhos de Jellinek (1960) que trouxeram cientificidade ao alcoolismo-doença.

Dentre as evidências que apontam para uma etiologia biológica para a dependência ao álcool, pode-se enumerar: risco de três a quatro vezes maior de desenvolver o quadro, caso o indivíduo tenha um parente em primeiro grau portador desta condição (Kapplan et al., 1997); maior concordância entre gêmeos monozigóticos (Pickens et al., 1991), que se mantêm, mesmo se os gêmeos forem criados separados dos pais (Schuckit, 1984); diferenças enzimáticas geneticamente associam-se com riscos diferenciados para o surgimento da dependência (Amit e Smith, 1985).

Embora exista uma maior concordância para dependência entre os idênticos quando comparados aos fraternos, esta concordância não é de cem por cento. Se os gêmeos ditos idênticos são geneticamente iguais e se a dependência fosse 


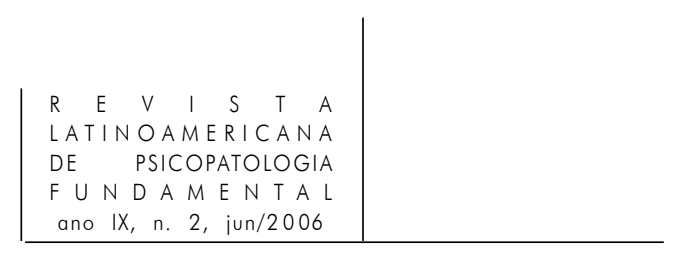

determinada apenas por questões genéticas, esperar-se-ia que a concordância entre os gêmeos monozigóticos fosse total, o que não é observado. Fica evidenciado que outros fatores estão envolvidos na etiologia da dependência ao álcool.

Em 1953 Straus e Bacon utilizando-se ainda da nomenclatura "alcoolismo", reconheciam que este se expressaria em distintos eixos: físico, psicológico e social. Tal forma de entendimento teve repercussões importantes: "o alcoolismo não deixou de ser considerado uma doença, mas o fato de se constituir em uma doença é apenas um dos inúmeros problemas encontrados (...). Nascia aí o conceito de problemas relacionados ao consumo de álcool, ampliando o conceito de alcoolismo, colocando-o numa perspectiva histórica e cultural” (Bertolote, 1997, p-26).

A compreensão de que existem diversos aspectos relacionados ao uso de bebida que extrapolam o cenário biomédico de dependência, está associada ao avanço da aplicação das Ciências Sociais na área da Saúde. Dessa colaboração, vem se delimitando dois campos: de um lado, o de síndrome de dependência ao álcool, associado ao território biomédico, e, de outro, o de problemas relacionados ao uso de álcool (Bertolote, 1997), que pode ser caracterizado como os efeitos adversos associados ao uso do álcool, independentemente de o padrão de ingesta do sujeito configurar uma situação de dependência. O campo dos problemas relacionados ao uso de álcool, dada a sua própria natureza, é aberto e polimorfo, visto que a fronteira que separa um beber normal de um problemático está estreitamente relacionada às dimensões socioculturais e históricas do beber (Edwards et al., 1999).

Existem diversas evidências que apóiam a idéia de que fatores sociais e culturais regulam a forma pela qual as pessoas fazem uso de bebidas alcoólicas e contribuem para a variação dos problemas relacionados ao uso de álcool entre diferentes grupos.

Um primeiro ponto é o fato de existirem culturas que estimulam a abstinência do uso de álcool, e outras que são permissivas (ibid.). Nas culturas mulçumanas, a influência sobre o beber é explicitamente negativa; nos países do mediterrâneo, o beber é ativamente endossado, sendo alta, nesses países, a prevalência de problemas clínicos associados ao beber, como a cirrose hepática, por exemplo.

Em um ponto intermediário, existem culturas que embora encorajem o uso de álcool possuem estratégias de regulamentação de seu uso. O sistema de regras se apresenta a partir da infância, quando se dá o processo de aprendizagem de como se deve beber.

Segundo Vaillant (1999), os italianos proporcionam às crianças uma longa educação no uso moderado do álcool e estimulam o ato de beber com os membros da família. Destaca que, na Itália, prevalece o uso de bebidas com baixo teor alcoólico, bem como o beber junto com as refeições. Informa que, como os 


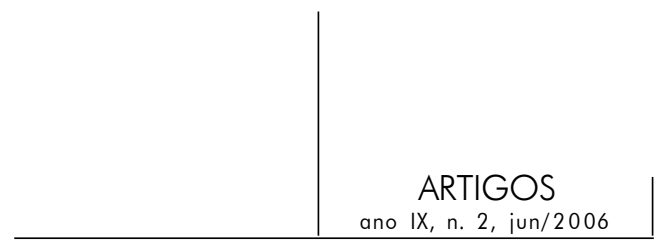

italianos, os franceses também ensinam suas crianças como beber, no entanto, não encorajam a moderação. Enquanto na Itália recusar-se a beber é aceitável, na França isto não se dá da mesma forma. Assim, “... na França, ao contrário da Itália, a embriaguez pública é tolerada” (p. 61).

Outra forma de se inferir a relação entre cultura e os problemas relacionados ao álcool é a observação de que diferentes culturas que ao influenciarem modos diversos de utilizar a bebida alcoólica associam-se a diferentes conseqüências negativas do beber. Edwards et al. (1999, p. 23-4), afirma:

... na França o consumo habitual de vinho nas refeições está associado a um consumo per capita alto e constante, que predispõe a complicações médicas crônicas como a cirrose e certos tipos de cânceres. Em centros urbanos do Reino Unido, particularmente entre homens da classe trabalhadora, é mais provável que o álcool seja consumido fora de casa e em geral numa grande quantidade durante as reuniões em bares. Este padrão de beber até a intoxicação parece estar mais acompanhado por conseqüências sociais adversas, tais como desarmonia conjugal, acidentes, violência interpessoal ou infrações por embriaguez. (p. 23-4)

Oyacer e Ñanco (1998) sintetizam a relação entre problemas relacionados ao uso de álcool e cultura ao afirmarem “que o beber é uma conduta e como tal não pode ser definida fora de seu contexto sociocultural, (e que), as patologias relacionadas com condutas e que implicam definições de normal e anormal podem variar de uma cultura para outra” (p. 36).

Contrapondo-se à tendência de centralizar as pesquisas em aspectos considerados problemáticos - dependência ou problemas relacionados ao álcool - sem investigar o papel de seu consumo em uma dada cultura, Menendez (1982) vêm propondo que as pesquisas deveriam priorizar o processo de alcoolização, ou simplesmente alcoolização. O conceito de alcoolização tem uma perspectiva mais abrangente, uma vez que busca subsidiar a compreensão do papel que o uso do álcool tem em uma dada sociedade. Assim, Menendez (1982) define alcoolização:

... o conjunto de funções e conseqüências positivas e negativas que cumpre a ingesta de álcool para conjuntos sociais estratificados, e não apenas o estudo dos alcoólicos dependentes, nem os excessivos, nem os moderados, nem os abstêmios, mas sim o processo que inclui a todos e que evita considerar o problema em termos de saúde e/ou enfermidade mental. (p. 63) do beber:

Langdon (2001) também enfatiza a importância da apreensão do significado

... se o álcool libera as inibições e leva a pessoa para um outro estado de ânimo, (...) o comportamento resultante desta liberação varia de um grupo para outro, porque valores diferentes estão sendo expressos. Assim, estar embriagado não se manifesta igualmente em todos os grupos, e é necessário considerar a cultura 


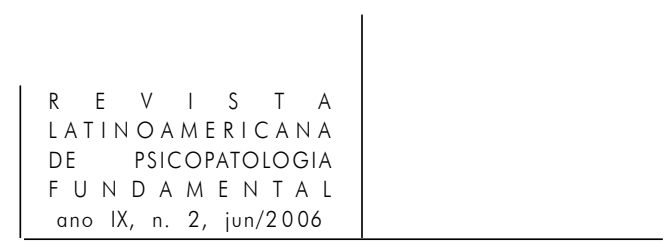

e os valores como fatores importantes nestas diferenças entre hábitos de beber e de como ficar bêbado. (p. 85)

A autora destaca o papel que a bebida tem em diversos povos, citando a caiçuma (bebida alcoólica tradicional) entre os Siona, utilizada para criar consenso diante de divergências políticas. Ao propor diretrizes para a pesquisa do "alcoolismo" entre povos indígenas, alinha-se com o conceito de alcoolização:

... quero enfatizar que a maneira de beber, como beber e quanto beber nas culturas indígenas têm sido definidos pela etnia específica, e que o consumo de bebidas fermentadas é uma manifestação das atividades constitutivas para o grupo social, expressando sensações e valores particulares. Porém, para muitos desses grupos as tradições de beber mudaram, (...) influenciadas pela introdução das bebidas destiladas, o processo de pacificação, e a inserção na sociedade nacional. (p. 86)

O conceito de alcoolização traz de forma clara a necessidade de contextualizar o uso de álcool, na cultura e na história e não apenas o uso problemático, buscando em última análise o significado que tem o beber para um dado grupo, em um determinado tempo.

\section{Estudos nacionais sobre o uso de álcool em populações indígenas}

Inicialmente enfatizamos que parte desta produção, sobretudo aquela em que os autores são ligados às ciências sociais, é influenciada pelas formulações de Langdon (2001), que ativamente critica o reducionismo biomédico: “... nossa ciência médica entende o alcoolismo como um fenômeno universal, no sentido de que a doença tem a mesma causa em todos os casos e que se manifesta igualmente em todos os contextos e em todas as culturas. Isto está longe de ser verdade. O que beber, quando beber, e o que beber variam de grupo para grupo” (p. 84).

Oliveira (2001), utilizando um enfoque antropológico, aborda a questão do "alcoolismo" entre os Kaingang. Relata que o uso de bebidas alcoólicas fermentadas é um costume antigo, associado tanto ao contexto religioso quanto ao profano, sendo regulamentado por diversas normas sociais. Defende que a introdução, de alambiques para a preparação de bebidas destiladas na época da conquista de seu território, está associada ao surgimento dos problemas relacionados ao uso de álcool nessa etnia. Para ela, o "alcoolismo" tem, por um lado, suas raízes na cultura tradicional e, por outro, na incorporação e transformação de costumes a partir da conquista, com a introdução da cachaça.

Ferreira (2001) realizou uma pesquisa sobre o tema em questão entre os Mbya-Guarani, do Rio Grande do Sul. Esse trabalho é de especial interesse por 


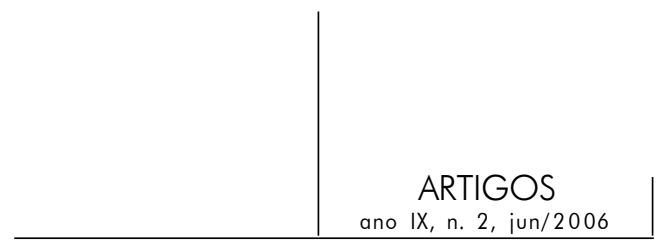

três motivos: primeiro, não utilizou, de forma genérica, a noção de “alcoolismo”, mas sim construiu uma categoria êmica "beber problema”; segundo, buscou compreender o fenômeno a partir da lógica nativa, articulando-a com a história de contato desses povos; terceiro, investigou alternativas de intervenção fundamentada no saber tradicional Mbya-Guarani.

Para a construção da categoria êmica “bebedor problema”, a autora observou que para os Mbya-Guarani não é importante saber se um indivíduo tem "uma dependência física e biológica do álcool” (p. 17). A forma de beber passa a ser vista como um problema a partir do momento em que começa a trazer impactos negativos para a vida do bebedor, de sua família e, sobretudo, de sua comunidade. Tal forma de compreensão da doença, segundo a autora, autoriza a sua investigação a partir do sistema médico tradicional Mbya-Guarani, visto que é dessa forma que outras situações passam a ser compreendidas como doenças.

Segundo Ferreira (ibid.), o processo colonizatório foi progressivamente dificultando que os Mbya-Guarani pudessem reproduzir o seu "modo de ser" (ñande rekó), em particular pela redução significativa de suas terras. A moradia em acampamentos na "beira” das estradas, sem terras agricultáveis, acaba distanciando o espírito dos índios lá residentes de Ñanderu, uma importante divindade Guarany. Viver nesses locais traz outro problema: a inexistência de Opy (casa de reza), visto que só pode haver Opy em terras Guarany. A casa de reza é o locus privilegiado do contato com o sagrado, ambiente onde se realizam e se atualizam os rituais, como os de cura, por exemplo. Ademais, onde não há Opy não existe Karaí (especialistas da medicina tradicional), que dentre outros recursos terapêuticos utilizam-se dos conselhos, proferidos através das "belas palavras”, que restabelecem as ligações entre os homens e Ñanderu. A compreensão do adoecimento está relacionada ao afastamento do espírito de Ñanderu dos Guarany, o que os vulnerabiliza aos ataques de espíritos maléficos. O “alcoolismo” é essencialmente interpretado dentro deste sistema, sendo visto como uma doença introduzida pelo branco, que reduziu o território Guarani e trouxe a cachaça; a associação desses elementos impede o exercício de seu "modo de ser", que acaba por separá-lo de Ñanderu. Uma vez distanciado, a “desproteção” favorece tanto o uso imoderado de álcool como os infortúnios dele decorrentes. Não havendo Opy nem Karaí, a religação com o divino torna-se difícil, permitindo que se feche o ciclo vicioso que permite a instalação e manutenção do "beber problema”.

Outras pesquisas de caráter epidemiológico vêm tentando efetuar abordagens quantitativas para apreender a problemática do uso de álcool entre populações indígenas brasileiras.

Kohatsu (2001) realizou estudo sobre o uso de álcool entre os Kaingang do Paraná. A autora verificou que na população estudada 26,8\% já fez uso de bebida 


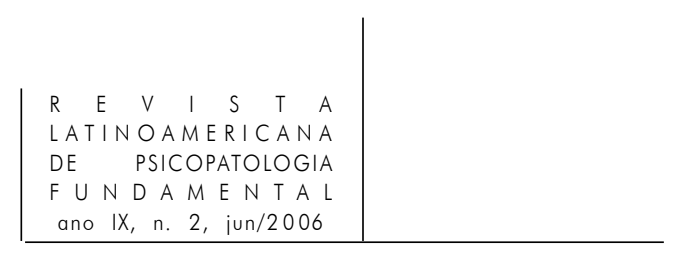

alcoólica e vem fazendo uso nos últimos anos. Quando avaliou essa freqüência por sexos, observou que $40,1 \%$ dos homens e $14,2 \%$ das mulheres se enquadraram nesta variável de uso de álcool. Comparando seus resultados aos de Souza J. (1996), que investigou a prevalência de dependência ao álcool em populações urbanas, concluiu que as proporções de consumo são maiores do que em populações não-indígenas. Pode-se comentar que o desenho metodológico utilizado por Kohatsu (2001), não tem o poder de determinação de problemas relacionados ao uso de álcool (tais como dependência ou abuso), visto que aborda exclusivamente o uso de bebida alcoólica, sem deixar claro se tal uso está associado ou não a algum tipo de problema socialmente reconhecido.

Albuquerque e Souza (1997) e Aguiar e Souza (2001) vêm desenvolvendo pesquisas epidemiológicas utilizando instrumentos padronizados para triagem de casos de dependência ao álcool de acordo com critérios biomédicos entre os índios Terena do Mato Grosso do Sul (1997 e 2001). Em 1997 realizaram um estudo de prevalência num conjunto de aldeias Terena. Avaliando a população com mais de 15 anos encontraram uma prevalência de alcoolismo de $18,8 \%$ (28,7\% entre os homens e $1,7 \%$ entre as mulheres). Posteriormente, em 2001, realizaram um estudo numa população Terena da periferia de uma cidade, encontrando uma prevalência de $11,5 \%$ para população acima de 15 anos (22,4\% entre os homens e $17,1 \%$ entre as mulheres). Uma importante contribuição desse estudo foi a observação do aumento da prevalência nas mulheres Terena que moram na periferia da cidade. Na comparação entre as duas realidades, observou também que as mulheres com dependência ao álcool das aldeias eram em geral de meiaidade, viúvas; já as mulheres da periferia eram mais novas e estavam trabalhando nas residências dos moradores da cidade. Os trabalhos realizados por esses autores podem ser questionados pelo fato de utilizarem critérios biomédicos, tidos como universais, para dependência ao álcool sem um questionamento sistemático de sua aplicabilidade em contextos socioculturais diferenciados. Tal fato pode ser problemático, já que em trabalho anterior demonstramos a dificuldade de utilização de critérios padronizados na realização de diagnóstico de alterações de comportamento em pacientes indígenas (Souza M., 2002).

Sobre esta produção nacional, observa-se que existem dificuldades em integrar o conhecimento produzido, problema que está, em parte, associado à utilização do termo "alcoolismo". Acredita-se que através da utilização de conceitos delimitados, parte das dificuldades de comunicação poderá ser superada. Podese afirmar que embora existam iniciativas que visem superar a dicotomia quantitativo/qualitativo, estas são ainda iniciais. De um lado, têm-se trabalhos que se aprofundam na busca de compreensão do processo de alcoolização (através de abordagens antropológicas) e outros que buscam quantificar a dependência ao álcool através de critérios biomédicos padronizados (através de métodos epide- 


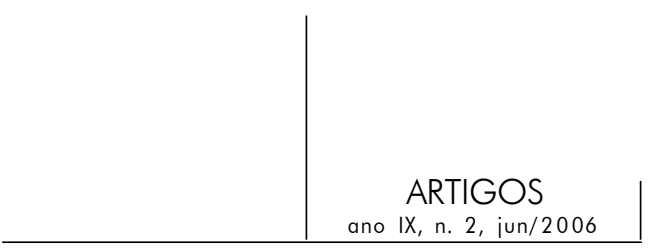

miológicos). Com exceção do trabalho de Ferreira (2001) não se observou trabalhos que busquem utilizar a categoria de problemas relacionados ao uso de álcool.

\section{Em busca de uma proposta integradora}

Uma vez apresentados os conceitos associados à questão do uso do álcool, e as estratégias para seu estudo em populações indígenas desenvolvidas no país, o que se esperaria, a princípio, é que fosse escolhido um dos conceitos, ou uma das abordagens para nortear o nosso olhar sobre esta temática. Entretanto, considerando a importância das diferentes formas de aproximação do objeto e dos diferentes conceitos apresentados, não vem sendo possível simplesmente escolher um em detrimento dos demais.

Nosso primeiro passo foi rejeitar o termo alcoolismo como categoria de análise, haja vista a sua inexatidão, que vem redundando em dificuldade de integração do conhecimento produzido, como se demonstrou a partir da revisão da literatura nacional sobre uso de álcool em populações indígenas.

O passo seguinte foi buscar compor um modelo conceitual que pudesse articular os diferentes conceitos anteriormente apresentados: dependência, problemas relacionados ao uso de álcool e alcoolização.

Na Figura 1 encontra-se esquematicamente apresentado o modelo conceitual aqui proposto para abordar a questão do uso do álcool. O conceito de alcoolização, representado pelo círculo maior, contém o conceito de problemas relacionadas ao uso do álcool e este último ao de dependência.

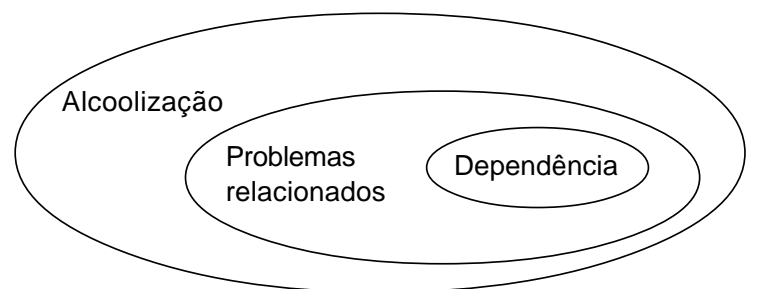

Figura 1 - Proposta de um modelo para integração dos conceitos de alcoolização, problemas relacionados ao uso do álcool e dependência ao álcool

A dependência ao álcool é o mais restrito dos conceitos, associando-se ao referencial biomédico. Problemas relacionados ao uso do álcool são de alcance mais amplo que o conceito anterior, associando-se tanto às ciências sociais quanto à biomedicina, abrangendo problemas de saúde e sociais; além de contextualizá- 


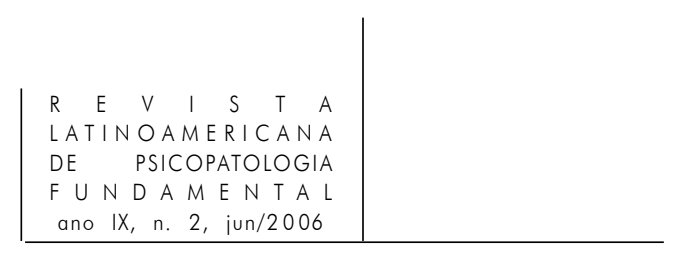

los em seu espaço social, cultural e histórico. O conceito de alcoolização contém os anteriores, e está ligado de forma mais clara ao domínio das ciências sociais, visto que se associa ao significado que o beber tem em uma dada cultura, independentemente de este ser problemático ou não. Em nossas investigações sobre a questão do uso de álcool por populações indígenas da região do Alto Rio Negro, temos buscado enfocar a questão a partir destas das três dimensões conceituais.

Considerando a primeira dimensão buscamos apreender o significado cultural atribuído à utilização de bebidas alcoólicas, as motivações para beber, as situações de consumo e os circuitos de embebedamento, buscando analisar estes aspectos através de uma perspectiva que considere a organização social destes povos e sua história de contato com a sociedade nacional.

Para realizarmos uma abordagem desta natureza vem sendo necessária a associação de um conceito claro de cultura. Uma das mais conhecidas definições de cultura, e por nós adotada, foi aquela formulada por Geertz (1986), que a descreve como uma teia de significados tecida pelo próprio homem, sustentando que a cultura tem um caráter dinâmico e heterogêneo, estando em constante construção, fornecendo uma diversidade de opções possíveis de caminhos a serem seguidos.

Tal forma de compreensão da cultura, a percebe como estando em constante reelaboração e reinvenção, diante dos acontecimentos e do andar da história. Para a temática do uso de álcool por populações indígenas, este conceito torna-se relevante, pois permite reconhecer o uso de bebidas alcoólicas como parte integrante da cultura dos indígenas, como também defende Langdon (2001); e conceber que a relação com o álcool pode estar sendo reelaborada frente às reacomodações do contato inter-étnico, iniciado há alguns séculos, como apontam autores nacionais (Oliveira, 2001; Quiles, 2001, Ferreira 2001).

Tentou-se investigar a dependência ao álcool a partir da utilização de critérios biomédicos estabelecidos, como aqueles contidos em um instrumento chamado CAGE, que já fora utilizado entre outros grupos indígenas brasileiros, como os Terena (Albuquerque e Souza, 1997; Aguiar e Souza, 2001) e os Kaingang (Oliveira, 2003). Entretanto, concluiu-se que a utilização do CAGE em populações indígenas do Alto Rio Negro era inadequada. Isso devido ao fato de a avaliação das respostas dos indígenas às perguntas contidas no instrumento, ter mostrado diversas inconsistências, quando se buscou articular teoricamente os pressupostos do instrumento às respostas fornecidas pelos entrevistados (Souza M., 2004). A inadequação do CAGE no contexto pesquisado não significa necessariamente que não exista dependência entre os entrevistados; o que ocorre é uma inviabilidade de detectar este quadro utilizando os critérios do referido instrumento.

A partir do questionamento dos critérios biomédicos, houve a necessidade de direcionar o olhar da pesquisa para a questão dos problemas relacionados ao uso de álcool. A questão central colocada é: quando o beber passa a ser entendido 
como um problema social? Ou, ainda, como se constrói a categoria êmica "bebedor problema", neste contexto específico? Ou seja, retoma-se as formulações de Straus e Bacon (1953) de uma forma genérica, e as de Oyacer e Ñanco (1998), de forma específica para as populações indígenas.

Dentro do processo investigativo, através de abordagens qualitativas, podese construir a categoria "beber problema" a partir da ótica nativa. A categoria construída pode ser decomposta em cinco eixos principais: uso em situações tidas como inadequadas (fora das festas e dos trabalhos coletivos); consumo de substâncias vistas como impróprias (álcool de farmácia, desodorante, perfume, por exemplo); apresentar comportamento disruptivo quando alcoolizado (tornarse violento, não se lembrar do que fez, não controlar a forma de beber); ter conseqüências adversas do beber (dificuldade para trabalhar, gastar mais do que o desejado); beber de tal for que seja um mau exemplo para os outros (filhos ou outros membros da comunidade).

Uma vez construída a categoria "beber problema", temos que direcionar esforços no sentido de elaborar um instrumento que possa ser utilizado para quantificação, a nível populacional, dos problemas relacionados ao uso do álcool. A relevância de um instrumento dessa natureza deve-se à sua importância estratégica na implantação das futuras intervenções, uma vez que possibilitará a identificação de áreas onde haja maior concentração de "bebedores problema”, bem como os grupos mais vulneráveis, permitindo tanto uma distribuição mais racional dos recursos a serem destinados para esta atividade, como a possibilidade de escolha de meios de prevenção mais adequados aos diferentes grupos afetados.

Desta forma, reconhece-se a importância de abordagens quantitativas para a pesquisa sobre o uso de álcool em populações indígenas, tal como foi observado nos trabalhos de Albuquerque e Souza (1997), Aguiar e Souza (2001) e Oliveira (2003). Por outro lado, aponta-se a possibilidade de não se trabalhar com o conceito de dependência, como fizeram os citados autores, mas sim utilizar para este fim o conceito de problemas relacionados ao uso de álcool, construído a partir de categorias nativas. Tal opção será relevante uma vez que permitirá identificar os subgrupos cuja forma de beber não vistas como destoantes do ponto de vista cultural, o que se presume terá utilidade futura no processo de busca de estratégias para mimização/superação dos problemas encontrados.

Esta perspectiva de trabalho que vemos como promissora, visa - além de superar as limitações associadas ao uso do conceito impreciso de "alcoolismo", através de uma maior clareza conceitual - apresentar estratégias para possíveis pesquisas de caráter quali-quantitativo que possam num futuro romper barreiras disciplinares, favorecendo um maior diálogo entre os campos do saber, que vemos como essencial para se abordar a questão do uso de álcool e em particular em populações culturalmente diferenciadas. 


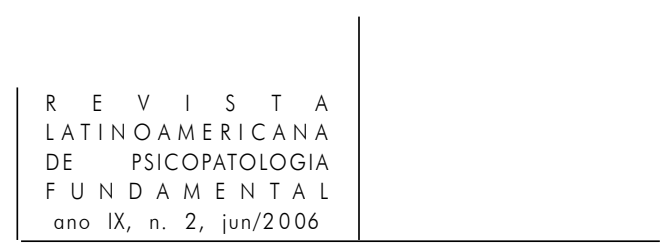

\section{Referências}

Aguiar, José Ivan e SouzA, Juberty Antônio. Alcoolismo em população Terena no Estado do Mato Grosso do Sul - impacto da sociedade envolvente. In: Seminário sobre Alcoolismo e DST/AIDS entre os povos indígenas. Brasília: Ministério da Saúde/ Secretaria de Políticas de Saúde/Coordenação Nacional de DST e AIDS, 2001. p. 149-65.

Albuquerque, Jia e Souza, Juberty Antônio. Prevalência do alcoolismo na população indígena Terena do Complexo Sidrolândia - Colônia Dois Irmãos. In: Anais da I Oficina Macro Regional de Estratégia, Prevenção e Controle das DST/AIDS para populações indígenas das Regiões Sul, Sudeste e do Mato Grosso do Sul. Brasília: Mistério da Saúde, 1997.

Аміт, Zalman e Sмітн, Brian R. A multidimensional examination of positive reinforce properties of acetaldehyde. Alcohol, v. 2, p. 367-70, 1985.

American Psychiatric Associaton - APA. Manual Diagnóstico e Estatístico de Transtornos Mentais - DSM IV. Porto Alegre: Artes Médicas, 1995.

Bertolote, José Manuel. Conceitos em alcoolismo. In: Ramos, Sérgio de Paula e Bertolote, José Manuel (orgs). Alcoolismo hoje. 3. ed. Porto Alegre: Artes Médicas, 1997. p. 17-31.

EDWARs, Griffith et. al. O tratamento do alcoolismo: um guia prático para profissionais de saúde. 3. ed. Porto Alegre: Artes Médicas, 1999.

FerreIra, Luciene Oliveira. Diagnóstico participativo antropológico sobre a manifestação do alcoolismo entre as sociedades indígenas no RS: subprojeto Mbya-Guarani. Porto Alegre, 2001. (Mimeo).

Gigliotti, Analice e Bessa, Marco Antônio. Síndrome de dependência ao álcool: critérios diagnósticos. Revista Brasileira de Psiquiatria, v. 26 (supl. I), p. 11-3, 2004.

JeLlineK, Emil Mercedes. The disease concept of alcoholism. New York: Hilhouse, 1960.

Kaplan, Harold et al. Compêndio de psiquiatria: ciências do comportamento e psiquiatria clínica. Porto Alegre: Artes Médicas, 1997.

Kohatsu, Marilda. O alcoolismo na comunidade Kaingang de Londrina. In: Seminário sobre Alcoolismo e DST/AIDS entre os povos indígenas. Brasília: Ministério da Saúde/Secretaria de Políticas de Saúde/Coordenação Nacional de DST e AIDS, 2001. p. 189-95.

LANGDOn, Esther Jean. O que beber, como beber e quando beber: o contexto sociocultural no alcoolismo entre as populações indígenas. In: Seminário sobre alcoolismo e DST/AIDS entre os povos indígenas. Brasília: Ministério da Saúde/Secretaria de Políti- 


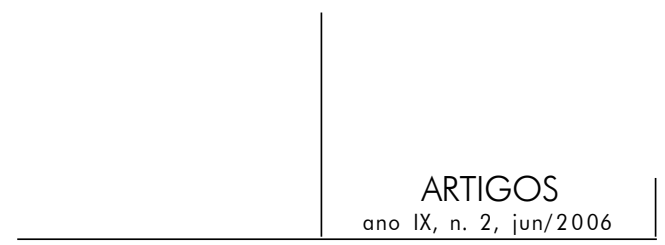

cas de Saúde/Coordenação Nacional de DST e AIDS, 2001. p. 83-97.

Menendez, E. L. El proceso de alcoholización: revisión critica de la produción socioantropologica, histórica y biomédica en America Latina. Cuaderno de la Casa Chata, v. 57, p. 61-94, 1982.

Oliveira, Marlene de. Alcoolismo entre os Kaingang: do sagrado e lúdico à dependência. In: Seminário sobre alcoolismo e DST/AIDS entre os povos indígenas. Brasília: Ministério da Saúde/Secretaria de Políticas de Saúde/Coordenação Nacional de DST e AIDS, 2001. p. 99-125.

Uso de bebidas alcoólicas e alcoolismo entre os Kaingang da Bacia do Rio Tibagi: uma proposta de interveção. In: Jeolas, L. S. e Oliveira, M. (orgs.). Anais do Seminário Cultura, Saúde e Doença. Londrina: as participantes, 2003. p. 43-65.

Organização Mundial de Saúde - OMS. Classificação de transtornos mentais e de comportamento da CID-10. Porto Alegre: Artes Médicas, 1993.

Oyacer, A. M. e Ñanco, J. Alcoholismo y etnia: criticas y propuestas. In: SAlgado, M. S. e Mella, I. J. (orgs.). Salud, cultura y território: bases para una epidemiologia intercultural. Lincanray: Ministerio de Salud Chile, 1998. p. 35-43.

Pickens, Roy W. et al. Heterogeneity in inheritance of alcoholism. Archives of General Psychiatry, v. 48, p. 19-28, 1991.

Quiles, Manuel Ignácio. Mansidão de fogo (aspectos etnopsicológicos do comportamento entre os Bororo. In: Seminário sobre alcoolismo e DST/AIDS entre os povos indígenas. Brasília: Ministério da Saúde/Secretaria de Políticas de Saúde/Coordenação Nacional de DST e AIDS, 2001. p. 167-88.

Schuскіт, Marc A. A subjective responses to alcohol in sons of alcoholics and control subjects. Archives of General Psychiatry, v. 41, p. 879-83, 1984.

SouzA, Juberty Antônio. Estudo epidemiológico descritivo de alcoolismo no Bairro Universitário de Campo Grande - MS. 1996. Dissertação (mestrado em Saúde Coletiva). Universidade Federal do Mato Grosso do Sul.

SouzA, Maximiliano Loiola Ponte. Reação Esquizofrênica em paciente indígena. Casos clínicos em psiquiatria, v. 4, n. 1-2, p. 30-2, 2002.

Alcoolização e violência no Alto Rio Negro. 2004. 198p. Dissertação (mestrado em Sociedade e Cultura na Amazônia). Universidade Federal do Amazonas.

Vulnerabilidade a dependência ao álcool em paciente indígena: relato de caso. Psychiatry On-Line Brazil, v. 10, janeiro de 2005. <http://www.polbr.med.br> Acesso em: 26 de abril de 2005.

Straus, Robert e Bacon, Selden. Drinking in College. New Haven: Yale University Press, 1953.

Vaillant, George. A história natural do alcoolismo revisitada. Porto Alegre: Artes Médicas, 1999. 


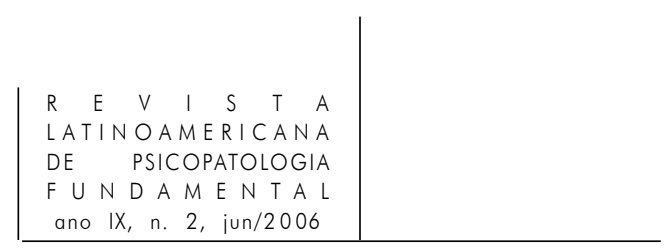

\section{Resumos}

A partir de una revisión de conceptos utilizados en la investigación sobre el uso de bebidas alcohólicas y de trabajos nacionales que envuelvan la cuestión del uso de alcohol por poblaciones indígenas se nota la dificultad generada por el uso indiscriminado de la noción del alcoholismo. Se presenta una propuesta inicial de un modelo teórico en el cual son articulados los conceptos de dependencia, problemas relacionados con el uso del alcohol y la alcoholización en el cual, se vienen rigiendo los autores en la construcción del objeto de investigación en el campo de la salud indígena en la región del Alto Rio Negro, noreste del departamento del Amazonas, Brazil.

Palabras claves: Alcoholismo, poblaciones indígenas, antropología de la salud, psiquiatria transcultural

À partir d'une révision de concepts utilisés dans la recherche sur l'usage des boissons alcoolisées et de travaux nationaux qui abordent la question de l'usage de l'alcool par les populations indiennes, on met en évidence la difficulté due à l'utilisation inconsidérée du terme "alcoolisme". On présente ici une proposition initiale de modèle théorique dans lequel sont articulés les concepts de dépendance, les problèmes en rapport avec l'usage de l'alcool et l'alcoolisation, que les auteurs rencontrent dans la construction de l'objet de recherche dans le domaine de la santé des populations indiennes de la région du Haut Rio Negro, dans le nord-ouest de l'Etat d'Amazonas, au Brésil.

Mots clés: Alcoolisme, populations indiennes, anthropologie de la santé, psyquiatrie transculturelle

The difficulty generated by the indiscriminate use of the notion of alcoholism becomes evident when one studies the concepts used in research on the use of alcoholic beverages, on the one hand, and Brazilian articles dealing with alcohol consumption by indigenous populations, on the other. An initial proposal for a theoretical model is presented. In order to articulate the concepts of dependence, alcohol-use-related problems, and alcoholization, which have guided researchers in the construction of the field of indigenous health in the Upper Rio Negro region, in the Northwest of the State of Amazonas.

Key words: Alcoholism, indigenous population, health anthropology, transcultural psychiatry

Versão inicial recebida em fevereiro de 2006

Versão revisada recebida em março de 2006 